\title{
Development and Analysis of 2D Flight Planning Search Engine Considering Fusion of Swim Data
}

\author{
Michael H. Sentoso ${ }^{1}$, Neno Ruseno ${ }^{2}$ \\ ${ }^{1,2}$ Aviation Engineering Department, International University Liaison Indonesia \\ MyRepublic Plaza 5th Floor, Jl. BSD Green Office Park, Tangerang, Banten \\ Email: neno.ruseno@iuli.ac.id
}

Received: April 11, 2021; Accepted : April 29, 2021; Published : May 1, 2021

\begin{abstract}
ABSTRCT
Flight planning is one of the essential factors of the airline operation. The selection of routes will determine the economic value of the flight. However, some conditions may prevent the flight to use the most optimum route due to airspace restriction or weather condition. The research aims to develop a search engine program that uses dynamic flight parameters that considers fusion of System Wide Information Management (SWIM) data including weather data and NOTAM to produce the most optimum route in 2D flight planning. The Dijkstra's pathfinding is implemented in Python programming language to produce the flight plan. The navigation data used is enroute airway in Indonesian FIR regions. The scenario used is a flight from Jakarta to Makassar with duration of 2 hours flight with considering the effect of restricted airspace and weather blockage during in-flight. The study also uses the optimum route produced by the algorithm to be compared with the possible alternate routes to define how optimum the route is. Adding a restricted airspace parameter will result in a new optimum flight plan that able avoids the airspace and the most minimum distance. The effect of external wind parameter could influence the optimum route which may vary depends on the speed of the wind.

Keywords: flight planning, SWIM data, Dijkstra's path finding, optimum route, restricted airspace.
\end{abstract}

\section{Introduction}

Before departure, a flight needs to have a flight plan that indicates the route that the flight will cross to reach the destination. A flight plan is usually filled by a pilot or flight dispatcher and will be sent to Air Traffic Control (ATC) authorities to be approved. Flight planning is considering several parameters including departure and arrival airport, time, aircraft type, engine type, speed, flight level and weather condition. For flight planning, weather conditions during the flight will impact airplane performance and variate the fuel consumption of the aircraft. It is called a dynamic flight plan because of the dynamic parameter inside the calculation like weather conditions that could change over time.

This study will focus on developing a route search engine program that consider the dynamic aspects of the flight like NOTAM release and weather that change over time. The search engine program can be used in various sectors in aviation, such as ATC, airline and other. ATC can use this search engine to update the flight plan of the aircraft when there is a NOTAM or weather problem that might risk the flight safety. Airline can use this program to search the most optimum route for the flight.

We present the review of latest publications about flight planning in Section 2, the Dijkstra's pathfinding algorithm in Section 3, and fuel required, flight time calculation and scenario presented in Section 4. Result and discussion are presented in Section 5. Conclusions and recommendations for future work are provided in Section 6.

\section{Literature Review}

In this section, we categorized the available publications on flight planning into 3 categories. We will start with dynamic flight plan that able to update flight plan dynamically including during flight. The second category is the air traffic planning and route optimization method. The last category is about SWIM data sharing of flight plan between different subscribers or organizations.

\subsection{Dynamic Flight Plan}

Dynamic flight plan is the key to achieving a safer and more efficient flight. One of the concepts for the dynamic flight plan allows the pilot to make a new or updated flight plan on board, this concept is efficient when the pilot needs to change the flight plan according to the parameter that is shown during the flight [1]. The pilot usually used a searching method that worked like the nowadays search engine like Google or Yahoo. The search engine will look for the runways of the designated airport [2].

Another method that can be used to update the flight plan is by using the ATC flight plan reference 
[3]. ATC received the flight plan from the FMS of the aircraft and updated it according to the situation of the air traffic. To re-produce a flight plan it can be done by entering the information into the FMS and computing the parameter based on the information given [4]. The it can use a memory inside the aircraft to store the flight plan and transfer it to the ground to be analysed [5].

For the re-planning due to weather, it is suggested to use the Dynamic Weather Route (DWR) tool. This tool able to predict the most efficient route based on the current actual weather situation [6]. The DWR tool monitors in-flight aircraft in en route airspace to find simple corrections to save flying duration.

\subsection{Air Traffic Planning and Route Optimization}

Constraints in creating a flight plan are the air traffic planning, flight route and air space capacity. Weather Impacted Traffic Index (WITI) matrix can be use to estimate air space capacity in degradation condition [7]. Another publication uses non-straight-line factors and air space restriction as a guide to formulate a better flight route for aircraft. It resulted in a safer and efficient flight plan [8]. In a busy airspace, a multi-level altitude intersection method is a way to avoid collision of the aircraft. The result of this study is to be able to get the busiest intersection and to know which bound is the busiest and which degree of angle of the intersection is being used the most for flight [9].

Another research proposes a 3D mesh network which consist of waypoints that conclude a centralised solution. It is optimum for small airports and decentralised. However, a hybrid approach is more suitable for large or multiple airports [10]. Other researcher proposed optimization on the separation between flights. Frechet distance method is used to minimize the duration between the aircraft to achieve more optimised air traffic [11]. One of the researchers found that during the night-time duration 8pm-4am have better efficiency rather than daytime in terms of air traffic [12]. The clustering method is also could be used to determine optimum condition of each flight route [13], [14].

\subsection{SWIM Concept for Flight Data Sharing Interoperability}

The Korea Airports Corporation (KAC) SWIM system uses Flight Information Exchange Model (FIXM), Aeronautical Information Exchange Model (AIXM) and Weather Information Exchange Model (WXXM) adapters to convert flight, airport and weather information into specific data types that can be read by the system [15]. These adapters are also responsible for managing and storing the data converted in the database system. The SWIM system not only provide request and response, but also publish and subscribe messaging for interfacing with other SWIM system in the world.

In SWIM data, flight objects can be used for sharing flight data among subscribers [16]. One of the approaches used is Semantic container which able not only to reduce the time consumption but also use the full potential of the SWIM which is interoperability in data sharing. Semantic container consists of set of data items (NOTAM, METAR), membership condition and administrative metadata [17]. The usage of data that is gathered from SWIM can be used to show flight mode changes at the waypoints to track and predict the flight mode transitions in real time for better air navigation system structure [18].

\section{Dijkstra's Pathfinding Algorithm and Data}

The main algorithm that will be used in this research is the Dijkstra's pathfinding algorithm. The algorithm is the core to find the best route for the aircraft to fly based on the waypoints and airways data network available. The SWIM data is used to support this algorithm to generate the optimum flight route.

\subsection{Dijkstra's Pathfinding Algorithm}

Dijkstra's pathfinding algorithm is used to determine the shortest path from start node to goal node inside a network of nodes, the shortest path is the result of the summation of distance of the shortest path node's distance. The algorithm will stop calculating when the shortest path from a single node is able to reach the goal node. Given the network of nodes is presented by equation below [19]:

$$
f\left(N_{n}\right)=\sum_{i=1}^{n} g\left(N_{i}\right)
$$

$$
\text { Where: } \begin{array}{ll} 
& g\left(N_{n}\right)=\frac{d}{v} \\
f\left(N_{n}\right) & : \text { Cheapest cost distance from from } N_{\text {end }} \text { to } N_{\text {start. }} \\
g\left(N_{i}\right) & : \text { Cost distance from node } \mathrm{N}_{i-1} \text { to node } \mathrm{N}_{i} \\
d & : \text { Distance to node from its parent node }(\mathrm{NM}) \\
v & : \text { Ground speed (kts) }
\end{array}
$$


The Equation (1) work by calculating the $f\left(N_{n}\right)$ by caching its parent node $\mathrm{N}_{n-1}$ and keep updating the $f\left(N_{n}\right)$ until reach the destination node, to get the nodes that being used can be done by retrieving the node stored in Nn-1 running backward from $N_{\text {end }}$ to $N_{\text {start }}$. The cost distance, Eq. 2 is the distance of a node from its parent node divided by the ground speed of the aircraft.

Dijkstra's pathfinding algorithm uses the distance between nodes which in this study is the distance between waypoints to waypoints or waypoints to airports as the search parameter. The departure airport will be the starting node and the arrival airport will be the goal node. The flowchart of Dijkstra's pathfinding is shown in Figure 1.

All the nodes will be assigned as unvisited nodes and set the distance in our starting node as zero. The starting node will be the current node and the algorithm will select all the unvisited nodes or that are connected to the current node or the neighbor node and put all the unvisited nodes to the visiting set and become the visiting node. All the visiting nodes will have their own tentative distance based on the summation of the current node tentative distance and the distance of the current node to the neighbor node, the visiting node also will store the current node as the reference route name. The current node will be marked as visited node; a visited node will never be checked again by the algorithm to avoid double calculation.

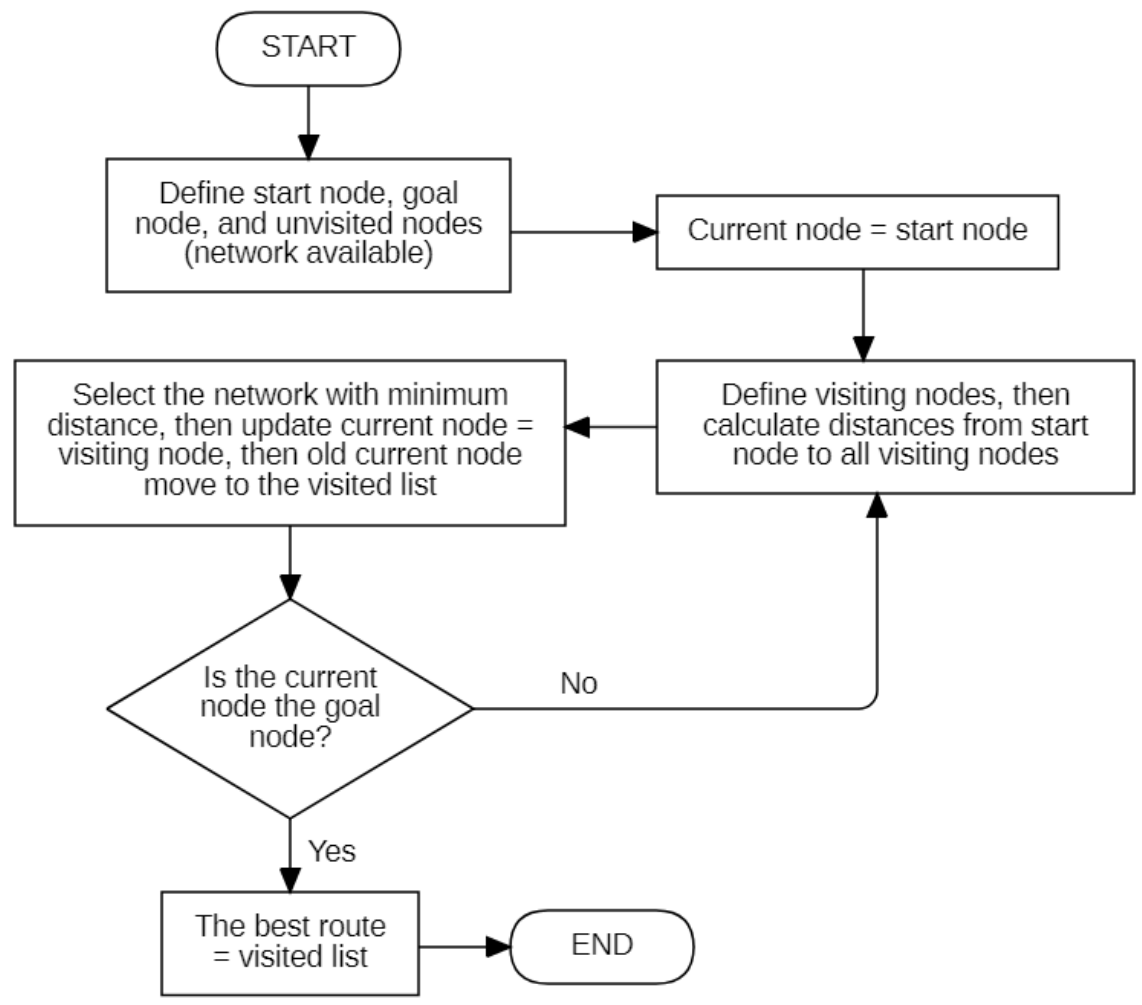

Figure 1. Flowchart of Dijkstra's pathfinding algorithm

In the visiting set, the algorithm will select the node that has the lowest tentative distance and set it as the current node. The current node will again select all the neighbor nodes and add it to the visiting set. The algorithm will not add the visited nodes, if the current is also connected to the nodes that are already inside the visiting set the algorithm, then will select the lowest tentative distance and it will change the value of the tentative distance of that node and will change the reference route name. This cycle will repeat until the current node is the goal node or the arrival airport. In this section will explain how the Dijkstra's pathfinding works in 3 conditions which are in normal condition, applied a restriction node and case with Headwind and Tailwind.

\section{a. Normal Condition}

Figure 2 show How Dijkstra's pathfinding algorithm works. In Figure 2(a) is when A node is the starting point and $\mathrm{F}$ node is the goal point, A node will be the current node and added to the visiting or open list with 0 cost distance. After visiting A node in Figure 2(b), it will visit all the nodes that are connected to the A node, the A node then will be removed from the open list then will be put in the visited list, this to prevent the node A to be visited again. Nodes B, C and D will be added into the open list to which the lowest cost distance will be in the first order. 
Figure 2(c), B node will be the current node as it has the lowest cost distance then it will select all the nodes connected to nodes B to be visited except the nodes in the visited list. Node $\mathrm{E}$ will be added to the open list, as node $\mathrm{C}$ already in the open list, the algorithm will update only the cost distance if it is lower than the current cost distance, so the cost distance from A to $\mathrm{C}$ will be 4 instead of 6 . The node $\mathrm{B}$ will be added into the visited list and the current list will have nodes C, D and E. Figure 2(d), Node C will be the current node and visit node $\mathrm{D}$ and $\mathrm{E}$, as both nodes already on the open list, this will only update the cost distance, $\mathrm{E}$ node will have new cost distance and $\mathrm{D}$ will have the same cost distance.

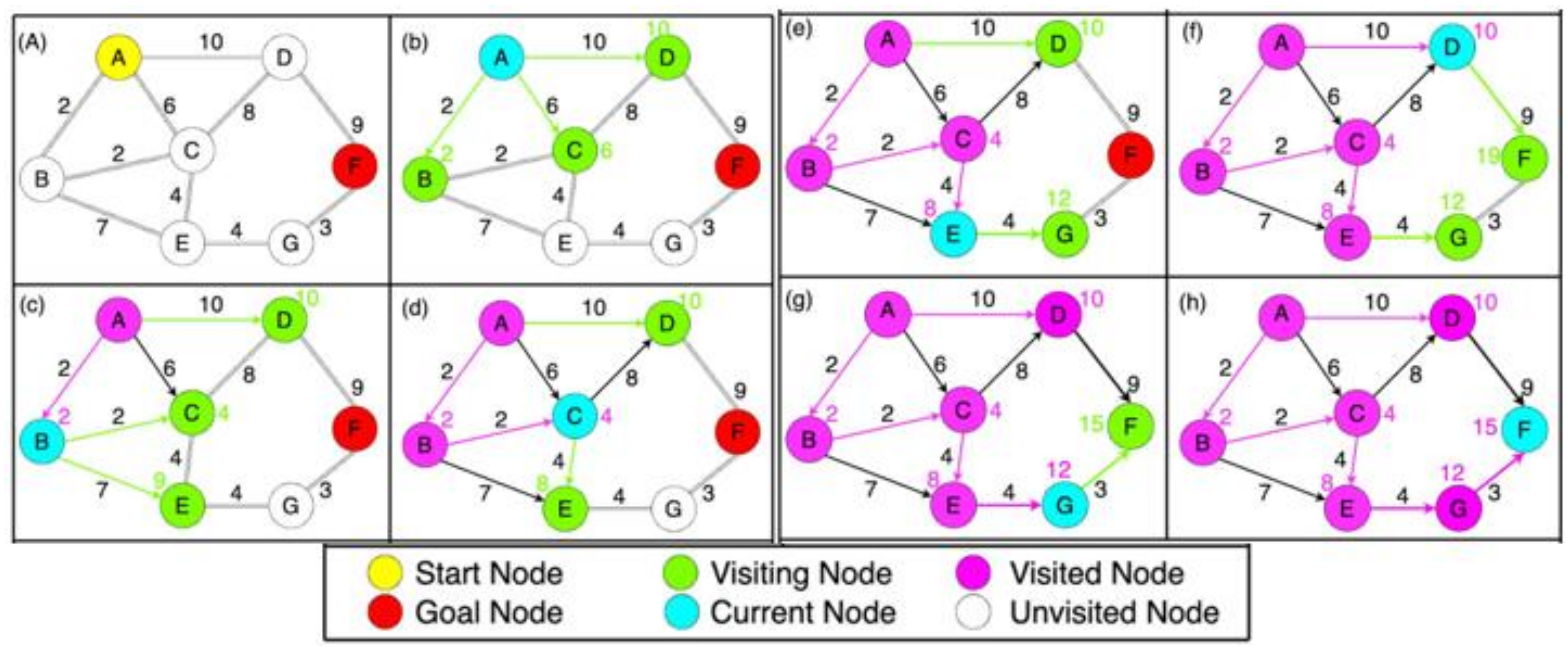

Figure 2. Diagram of Dijkstra's pathfinding algorithm.

Figure 2(e), Node E will be the current node, and visit node G. Figure 2(f), the algorithm will select node D, and will visit node F or the Destination node, this will not stop the algorithm as F node have the higher cost distance of 19 . Figure $2(\mathrm{~g})$, now the algorithm will visit $F$ node again, but this time will visit it from node $\mathrm{G}$, as the cost distance from node $\mathrm{G}$ to $\mathrm{F}$ is lower than from node $\mathrm{D}$ to $\mathrm{F}$ the cost distance will be updated.

Figure 2(h), as F node is the only unvisited node left, it will be selected as the current node and it will stop the algorithm, the result of the algorithm will be $\mathrm{A} \rightarrow \mathrm{B} \rightarrow \mathrm{C} \rightarrow \mathrm{E} \rightarrow \mathrm{G} \rightarrow \mathrm{F}$. The algorithm will select the shortest path possible even if it will take more nodes as it will select the lowest cost distance from starting node to goal node. This algorithm will result the shortest path or route for the aircraft, the result will also state all the waypoints that will be flown in this route to inform the flow of the route.

\section{b. Case with Restriction Node}

There will be time when airspace is not available for the flight to fly over it, this will need the pathfinding algorithm to be able to add restricted airspace into the algorithm before the calculation. The algorithm will work the same way as normal, but node inside the restricted airspace will be removed. For example, the node B in Figure 2 is inside the restricted airspace. Thus, it is removed from the list of available nodes.

The flow is still the same, except without node $\mathrm{B}$. The result of the most optimum route is $\mathrm{A} \rightarrow \mathrm{C} \rightarrow \mathrm{E} \rightarrow$ $\mathrm{G} \rightarrow \mathrm{F}$, with 17 cost distance. The generated route has a higher cost distance than the first optimum route because of the restriction on nodes.

\section{c. Case with Headwind and Tailwind}

Headwind is the wind that flows in the opposite direction of the flight, this will affect the flight performance as the drag force of the aircraft will increase, so the engine needs to increase the thrust to maintain the aircraft speed, or the flight will have longer duration to reach the destination. Tailwind is the opposite of the headwind as it is wind that flows in the same direction of the flight; hence it will increase airspeed and shorten the flight duration.

Headwind and Tailwind are components that will differentiate flight path calculation, this will affect most long-haul flights as it affects the aircraft performances as the longer an aircraft flies the longer will the effect of the wind to the aircraft. A route with longer flight distance can be reached in a shorter duration than the route with shorter distance if there are wind conditions that benefit the flight in the longer route.

In the program as it cannot alter the speed depending on the route, so the change will affect in the distance instead, if the speed of the aircraft in that route increase that will decrease the distance, this also happen when the aircraft is struggling to keep up the speed in particular route hence it will increase the 
distance in this algorithm. After entering the wind speed on a route, the algorithm will change the distance in that route depending on the wind speed input. For example, network that is used in the Figure 1 with the wind speed decreases the distance on node A-D and D-F by $30 \%$ of the distance.

The result of the most optimum route is $\mathrm{A} \rightarrow \mathrm{D} \rightarrow \mathrm{F}$, with cost distance of 13.3. From this example, it shows that the wind speed in certain routes might benefit the flight duration and become much shorter than the optimum route. If the wind speed in this example is stronger and decreases the distance even-more, the algorithm might not have to visit the below node to end the algorithm and generate the result.

\subsection{SWIM Data}

System Wide Information Management (SWIM) is a method for Air Traffic Management (ATM) to interoperable exchanging information of aeronautical, flight and weather data from and to approved airspace users. With the SWIM method the ATM will receive and read the data from other ATMs without converting the data format. With the SWIM method, ATM will provide regulated and secure data for the stakeholder. SWIM consists of AIXM, NOTAMs, FIXM and WXXM.

Aeronautical Information Exchange Model (AIXM) design to enable Aeronautical Information Service (AIS) and other users to supply and consume digital format of aeronautical data with higher efficiency in time, cost, and safety. Information related to AIXM including aerodrome, airspace structure, flight routes, procedure, restriction, and NOTAM [15].

NOTAMs (Notice to Airmen) is a notice to alert aircraft pilots with the disturbance or hazard that could risk the safety of the flight, NOTAMs are published in advance or in an emergency like volcano eruption or military emergency the publication reacts to the situation. NOTAMs release will notify the operating flight personnel about the alteration about the aeronautic facility, service, procedure, or emergency condition that will affect the safety of the flights.

Flight Information Exchange Model (FIXM) is designed for the interoperability of stakeholder in exchanging flight and flow of aircraft data. The stakeholder will be able to subscribe, collect, verify flight data even if a different version of FIXM is implemented [15].

Weather Information Exchange Model (WXXM) is designed for the compatibility of weather data exchange even with different ATM systems. With this interoperable system weather data like Meteorological Aerodrome Report (METAR) will be accessible by various ATC or pilot, it will increase current situational awareness of the weather hence flight safety can be guaranteed [15].

SWIM able to not only reduce the time consumption but also the full potential of the SWIM, which is interoperability in data sharing, semantic container consists of set of data items (NOTAM, METAR), membership condition and administrative metadata (provenance, quality, technical) [17].

\section{Flight Parameters Calculation and Scenarios}

Once the flight route is defined in a flight planning, it is required to calculate some flight parameters. Two of them which are very important in a flight planning are fuel required and flight duration.

\subsection{Fuel Requirement}

Fuel consumption is one of the main aspects of flight planning, it is crucial to know how much fuel is needed for the flight including the additional fuel for safety measures. Fuel calculation will be affected by all the flight planning parameters, including restriction airspace, and weather condition. As increase or decrease in predicted aircraft flight performance will also alter the fuel consumption of the aircraft for the flight.

$$
\begin{gathered}
F c=\frac{F r}{D} \\
C=D * F C * g
\end{gathered}
$$

Where:

$$
\begin{aligned}
& F c=\text { Fuel consumption }(\mathrm{kg} / \mathrm{h}) \\
& F r=\text { Total fuel required }(\mathrm{kg}) \\
& D=\text { flight duration (hour) } \\
& C=\text { fuel cost for the flight (US dollar) } \\
& g=\text { fuel cost per gallon (US dollar/gallon) }
\end{aligned}
$$

Equation (3) calculates the fuel consumption of an aircraft based on the total fuel required divided by the flight duration. According to the reference [20] the average fuel consumption of Boeing 737-800 is 6.123 
$\mathrm{kg} / \mathrm{NM}$, as $1 \mathrm{~kg}=0.264$ gallon. The fuel consumption will be 1.6175 gallon $/ \mathrm{NM}$.

From the fuel consumption it will be possible how much gallon of jet fuel is needed for a flight based on the flight duration. For fuel pricing, referring to Pertamina [21] one liter of jet fuel is 46.7 cent/liter, which is equal to 1.77 USD/ gallon before tax. After including tax, the cost of 1 gallon of jet fuel is 1.95 USD. Equation (4) shows the fuel cost for the flight based on the aircraft, duration of flight and fuel cost per gallon in US Dollar.

\subsection{Flight Duration}

In flight planning, there are several routes that can be flown to reach the destination airport. Just like google maps or other navigation software, the goal is to give the user the quickest route possible by considering all the routes available with their parameter. For flight planning the defining parameter is the weather condition. The weather condition has few parameters that should be considered for the flight planning, including current condition, en-route forecast condition, destination condition and wind aloft. The wind aloft during en-route phase will certainly affect the performance of the aircraft, as aircraft spend most of the time in cruising phase.

If the wind that present during en-route is reach a certain amount, a route that have longer distance can be more economic than the shorter route. Because of the strong tail wind will increase the groundspeed of the aircraft. Thus the aircraft will more efficient in the fuel consumption.

To calculate how strong headwind or tailwind that can affect the selected route outcome, in this thesis will use the total distance of the most optimum route divided by the average speed of the aircraft for this route, the outcome will be the benchmark for analysis. Headwind and tailwind affect the speed of the aircraft, so the average speed of the aircraft will increase and decrease by 1 knot and will be divided to the total flight distance, the outcome will be the percentage of how much percentage of flight duration will be swift by the change of the average speed. Equation (5) calculates the average speed of an aircraft.

$$
\begin{gathered}
F S=\frac{F d i s}{F d u r} \\
a=\left(1-\left(\frac{F d i s}{F S+1} * \frac{F S}{F d i s}\right)\right) * 100 \% \\
A=F d u r *(1+(a * w))
\end{gathered}
$$

Where:

$$
\begin{aligned}
& F d i s=\text { Flight Distance (NM) } \\
& F d u r=\text { Flight Duration (hours) } \\
& F S=\text { Flight Speed (kts) } \\
& \text { a }=\text { Percentage of flight duration change per } 1 \mathrm{kts} \\
& A=\text { Affected flight duration (hour) } \\
& w=\text { winspeed (kts) }
\end{aligned}
$$

This percentage (Equation (6)) will be calculated into the optimal route to generate how strong the headwind to be present to make the route not optimal. The percentage also will be the parameter for the alternate route, to know how strong the tailwind should be generated by the weather to make the alternate route more economical. Equation (7) shows how flight distance changes with the alteration of windspeed.

In this study the wind speed range will be from -100 to $100 \mathrm{kts}$ using the multiple of 5. So, there will be a total of 41 samples of flight distance consisting of 1 original sample and 40 altered samples. Each of the sample then will be divided by the average speed of the aircraft for the flight to get the flight duration based on the change of wind.

Each route will have 41 samples of flight duration then will graph in one diagram as one route will be represented as a line in the graph for comparison. The $\mathrm{X}$ axis will be the variation of wind speed and the $\mathrm{Y}$ axis will be the duration of the flight.

\subsection{Flight Scenario}

The result of the flight route search engine will give the route that has the lowest flight distance. This will provide the pilot or flight dispatcher the most optimal route during normal conditions. But the weather is dynamically changing. Thus, flight planning needs to dynamically change according to the current weather.

This study uses a flight which have the starting airport of Soekarno-Hatta International Airport, which is in Tangerang, Banten. This airport is the main hub of all international and domestic flight in Indonesia. There 
Development and Analysis of 2D Flight Planning Search Engine Considering Fusion of Swim Data

will be a lot of airways connected to this airport that will be resulted in the substantial option for alternate route than other airports.

This research will use a domestic flight to analyze the effect of weather to the result in flight planning. For the case study will be a medium range flight that will take around 2 hours. It is the flight from SoekarnoHatta International Airport to Sultan Hasanuddin International Airport in Makassar, South Sulawesi.

\section{Result and Discussion}

Each case study consists of the optimum route generated by the algorithm implemented in Python programming language, the optimum route when airspace restriction is applied and route optimization analyses comparing the optimum route with the alternate routes selected.

\subsection{Optimum Flight Route}

The distance from Jakarta to Makassar is almost $1433.26 \mathrm{~km}$ in great circle distance or 773.9 NM. From the calculation of the most optimum and most used flight route it accumulated a total flight distance of 788 NM. The average speed of the aircraft for this flight is 394 kts.

After putting in Soekarno-Hatta and Sultan Hasanuddin as departure and arrival airports, the search engine program will generate a navigation log and map for visualization. The Navigation $\log$ (Table 1) stated that the flight will take 2 hours to complete and fuel around 1275 gallons for the trip. From the navigation log it also stated the waypoints that need to be taken to fly the most optimum flight. From take-off the aircraft need to fly over Halim (HLM) VOR and continue to Cirebon (CA) before entering java sea by waypoints TELET, LUNAS, WAWAN, HEREN and OVINA to reach Makassar (Figure 3) in 2 hours.

For comparison, the flight path of Garuda Indonesia flight GA 616 on 23 July 2020 has the similar route [22]. For this flight needs approximately 1275 gallon of fuel with the ATF price is at 1.95 USD/gallon after tax, the total amount that the airlines need to spend is around 2486 USD or around Rp. 37.3 million.

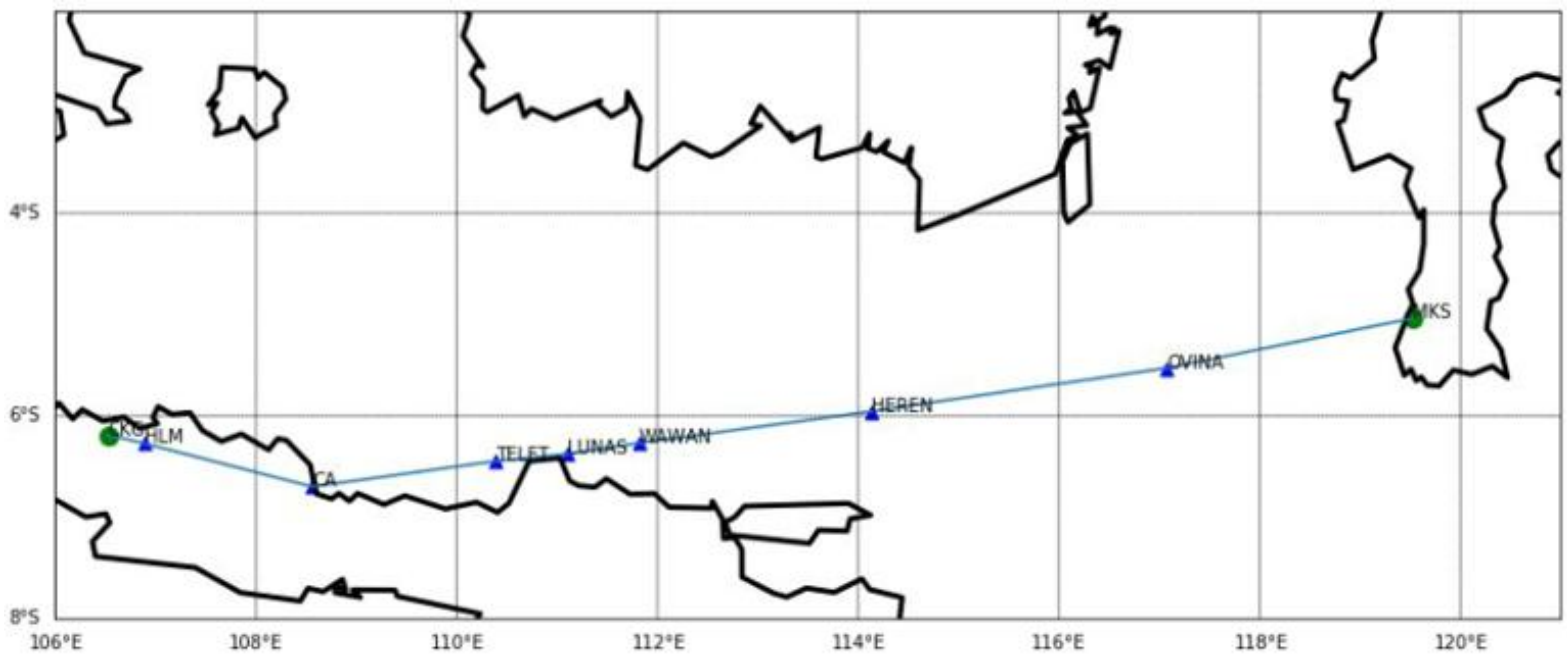

Figure 3. The optimum route generated by the program from Jakarta-Makassar Flight.

Table 1. Navigation Log of Optimum Route Jakarta-Makassar Flight.

\begin{tabular}{|c|c|c|c|c|}
\hline Waypoint & $\begin{array}{l}\text { Latitude } \\
\text { Longitude }\end{array}$ & $\begin{array}{l}\text { Distance }[\mathbf{N M}] \\
\text { Acc. Dist. }[\mathbf{N M}]\end{array}$ & $\begin{array}{l}\text { Duration [hh:mm:ss] } \\
\text { Total Duration } \\
\text { [hh:mm:ss] }\end{array}$ & $\begin{array}{l}\text { Fuel Req. [US gal.] } \\
\text { Total Fuel Req. [US gal.] }\end{array}$ \\
\hline CKG & $\begin{array}{l}\text { S 0611'16”' } \\
\text { E } 106^{\circ} 31^{\prime} 48^{\prime \prime}\end{array}$ & $\begin{array}{l}0 \\
0\end{array}$ & $\begin{array}{l}\text { 00:00:00 } \\
\text { 00:00:00 }\end{array}$ & $\begin{array}{l}0 \\
0\end{array}$ \\
\hline HLM & $\begin{array}{l}\text { S } 06^{\circ} 16^{\prime} 19^{\prime \prime} \\
\text { E } 106^{\circ} 53^{\prime} 13^{\prime \prime}\end{array}$ & $\begin{array}{l}22 \\
22\end{array}$ & $\begin{array}{l}00: 03: 21 \\
00: 03: 21\end{array}$ & $\begin{array}{l}35.59 \\
35.59\end{array}$ \\
\hline $\mathbf{C A}$ & $\begin{array}{l}\text { S 0641'53”' } \\
\text { E } 108^{\circ} 33^{\prime} 35^{\prime \prime}\end{array}$ & $\begin{array}{l}103 \\
125\end{array}$ & $\begin{array}{l}00: 15: 41 \\
00: 19: 02\end{array}$ & $\begin{array}{l}166.6 \\
202.19\end{array}$ \\
\hline TELET & $\begin{array}{l}\text { S } 06^{\circ} 26^{\prime} 47^{\prime \prime} \\
\text { E } 110^{\circ} 23^{\prime} 29^{\prime \prime}\end{array}$ & $\begin{array}{l}110 \\
235\end{array}$ & $\begin{array}{l}00: 16: 45 \\
00: 35: 47\end{array}$ & $\begin{array}{l}177.92 \\
380.11\end{array}$ \\
\hline LUNAS & S $06^{\circ} 22^{\prime} 33^{\prime \prime}$ & 44 & 00:06:42 & 71.17 \\
\hline
\end{tabular}




\begin{tabular}{lllll}
\hline & E $111^{\circ} 06^{\prime} 21^{\prime \prime}$ & 279 & $00: 42: 29$ & 451.28 \\
WAWAN & S $06^{\circ} 16^{\prime} 06^{\prime \prime}$ & 42 & $00: 06: 24$ & 67.94 \\
& E $111^{\circ} 49^{\prime} 15^{\prime \prime}$ & 321 & $00: 48: 53$ & 519.22 \\
HEREN & S $05^{\circ} 57^{\prime} 21^{\prime \prime}$ & 140 & $00: 21: 19$ & 226.45 \\
& E $114^{\circ} 08^{\prime} 07^{\prime \prime}$ & 461 & $01: 10: 12$ & 745.67 \\
OVINA & S $05^{\circ} 31^{\prime} 48^{\prime \prime}$ & 177 & $00: 26: 57$ & 286.3 \\
& E $17^{\circ} 04^{\prime} 12^{\prime \prime}$ & 638 & $01: 37: 09$ & 1031.96 \\
MKS & S $05^{\circ} 02^{\prime} 16^{\prime \prime}$ & 150 & $00: 22: 51$ & 242.62 \\
& E $119^{\circ} 31^{\prime} 34^{\prime \prime}$ & 788 & $02: 00: 00$ & 1274.59 \\
\hline
\end{tabular}

\subsection{Optimum Flight Route}

This is the scenario when there is an airspace being restricted by the NOTAM when the aircraft is in the cruising phase. The optimum route that is generated by the program and the restricted airspace that appears in the waypoint TELET, the restricted airspace is informed when the aircraft is making their way to Makassar and currently is approaching Cirebon.

Table 2 is the navigation log that is generated by the program when inputting the next waypoint as the starting point and the restricted airspace into the calculation. So now the flight route will change, instead of flying from CA to TELET the flight will then fly to PIALA waypoint and Semarang before continuing to approach Makassar via Java Sea. Figure 4 is the visualization of the new alternate generated by the program to avoid the restricted airspace.

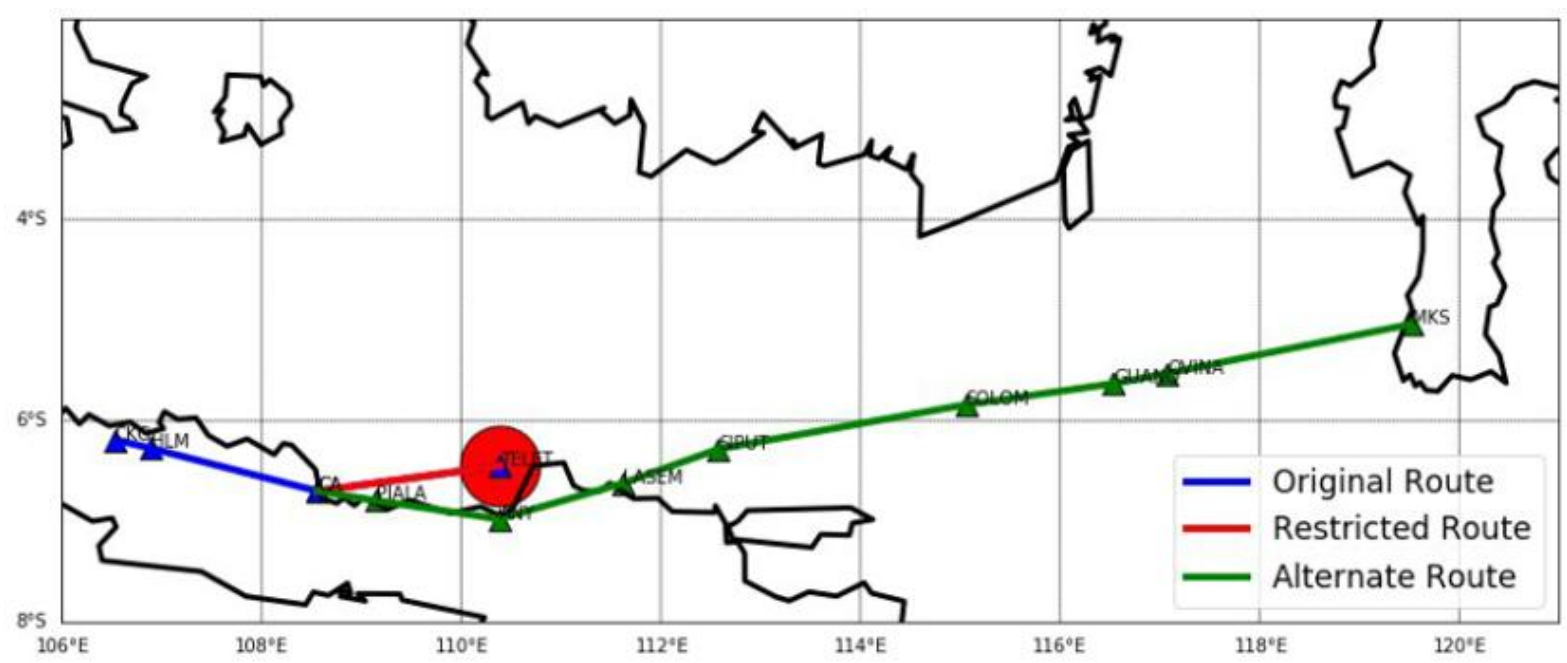

Figure 4. The optimum route with in-flight update due to restricted airspace.

Table 2. Navigation Log with in-flight update for optimum flight route Jakarta to Makassar.

\begin{tabular}{|c|c|c|c|c|}
\hline Waypoint & $\begin{array}{l}\text { Latitude } \\
\text { Longitude }\end{array}$ & $\begin{array}{l}\text { Distance }[\mathbf{N M}] \\
\text { Acc. Dist. [NM] }\end{array}$ & $\begin{array}{l}\text { Duration [hh:mm:ss] } \\
\text { Total Duration } \\
\text { [hh:mm:ss] }\end{array}$ & $\begin{array}{l}\text { Fuel Req. [US gal.] } \\
\text { Total Fuel Req. [US gal.] }\end{array}$ \\
\hline \multirow[t]{2}{*}{ CA } & S 0641'53”' & 0 & 00:00:00 & 0 \\
\hline & E $108^{\circ} 33^{\prime} 35^{\prime \prime}$ & 0 & 00:00:00 & 0 \\
\hline \multirow[t]{2}{*}{ PIALA } & S 0647’24”' & 35 & $00: 04: 38$ & 56.29 \\
\hline & E $109^{\circ} 08^{\prime} 24^{\prime \prime}$ & 35 & 00:04:38 & 56.29 \\
\hline \multirow[t]{2}{*}{$\mathbf{A N Y}$} & S 0658’29”' & 75 & 00:09:59 & 121.15 \\
\hline & E $110^{\circ} 22^{\prime} 48^{\prime \prime}$ & 110 & $00: 14: 38$ & 177.44 \\
\hline \multirow[t]{2}{*}{ LASEM } & S 06³7’12” & 77 & $00: 10: 14$ & 124.06 \\
\hline & E $111^{\circ} 37^{\prime} 12^{\prime \prime}$ & 187 & $00: 24: 51$ & \\
\hline
\end{tabular}




\begin{tabular}{|c|c|c|c|c|}
\hline & & & & 301.5 \\
\hline SIPUT & $\begin{array}{l}\text { S } 06^{\circ} 16^{\prime} 48^{\prime \prime} \\
\text { E } 112^{\circ} 34^{\prime} 48^{\prime \prime}\end{array}$ & $\begin{array}{l}61 \\
248\end{array}$ & $\begin{array}{l}\text { 00:08:09 } \\
\text { 00:33:00 }\end{array}$ & $\begin{array}{l}98.83 \\
400.33\end{array}$ \\
\hline SOLOM & $\begin{array}{l}\text { S } 05^{\circ} 50^{\prime} 24^{\prime \prime} \\
\text { E } 115^{\circ} 03^{\prime} 36^{\prime \prime}\end{array}$ & $\begin{array}{l}150 \\
398\end{array}$ & $\begin{array}{l}00: 20: 04 \\
00: 53: 04\end{array}$ & $\begin{array}{l}243.43 \\
643.76\end{array}$ \\
\hline GUANO & $\begin{array}{l}\text { S } 05^{\circ} 37^{\prime} 48^{\prime \prime} \\
\text { E } 116^{\circ} 32^{\prime} 24^{\prime \prime}\end{array}$ & $\begin{array}{l}89 \\
487\end{array}$ & $\begin{array}{l}00: 11: 55 \\
01: 04: 59\end{array}$ & $\begin{array}{l}144.6 \\
788.37\end{array}$ \\
\hline OVINA & $\begin{array}{l}\text { S } 05^{\circ} 31^{\prime} 48^{\prime \prime} \\
\text { E } 117^{\circ} 04^{\prime} 12^{\prime \prime}\end{array}$ & $\begin{array}{l}32 \\
519\end{array}$ & $\begin{array}{l}00: 04: 15 \\
01: 09: 14\end{array}$ & $\begin{array}{l}51.6 \\
839.97\end{array}$ \\
\hline MKS & $\begin{array}{l}\text { S } 05^{\circ} 02^{\prime} 16^{\prime \prime} \\
\text { E } 119^{\circ} 31^{\prime} 34^{\prime \prime}\end{array}$ & $\begin{array}{l}150 \\
669\end{array}$ & $\begin{array}{l}00: 20: 00 \\
01: 29: 14\end{array}$ & $\begin{array}{l}242.62 \\
1082.59\end{array}$ \\
\hline
\end{tabular}

\subsection{Route Optimization Analysis}

Four routes are selected to be analyzed for the flight to Makassar from Jakarta and the visualization is shown in Figure 5. The first route or the optimal route is to fly over north of west java until reaching Cirebon and then turning left to enter the Java Seas to reach Makassar. The second route or the alternative route is the same as route 1 until reaching Cirebon, instead of fly straight to Java Sea, the aircraft continue to fly above the north coast of central java until reaching Surabaya, after reaching Surabaya the aircraft then will fly over Madura and Java Sea to reach Makassar. The third route or alternative route 3 had a different flight approach, instead of flying to Cirebon, the aircraft will fly straight crossing the java sea to reach Banjarmasin, after reaching Banjarmasin the aircraft will continue to GURNI waypoint to reach Makassar. The last route or the alternative route 3 , will have same approach as alternative route 2 to straight crossing the java sea but this route will reach LAMUD waypoint, waypoint is on the Tanjung Puting National Park and the aircraft will turn to KEVOK waypoint before reaching Makassar.

The average flight duration for the optimum route is 2 hours. If it is divided by the distance of the flight distance of route 1 which is 788 Nautical Miles, we can have the average speed of the flight is 394 kts. If the same speed used to fly the other route will result in flight duration of 2 hours 3 minutes for route 2, 2 hours 4 minutes and 2 hours 8 minutes for route 3 and route 4 respectively. But all this condition is only applicable in the normal condition when the wind generated by the weather does not affect the aircraft performance. As the search engine is based on the distance between the nodes, the increase or decrease of the average speed of the aircraft will affect the increase or decrease of the air distance between nodes in the calculation. The search engine will only change the distance between waypoints in the aircraft cruising phase and descent phase.

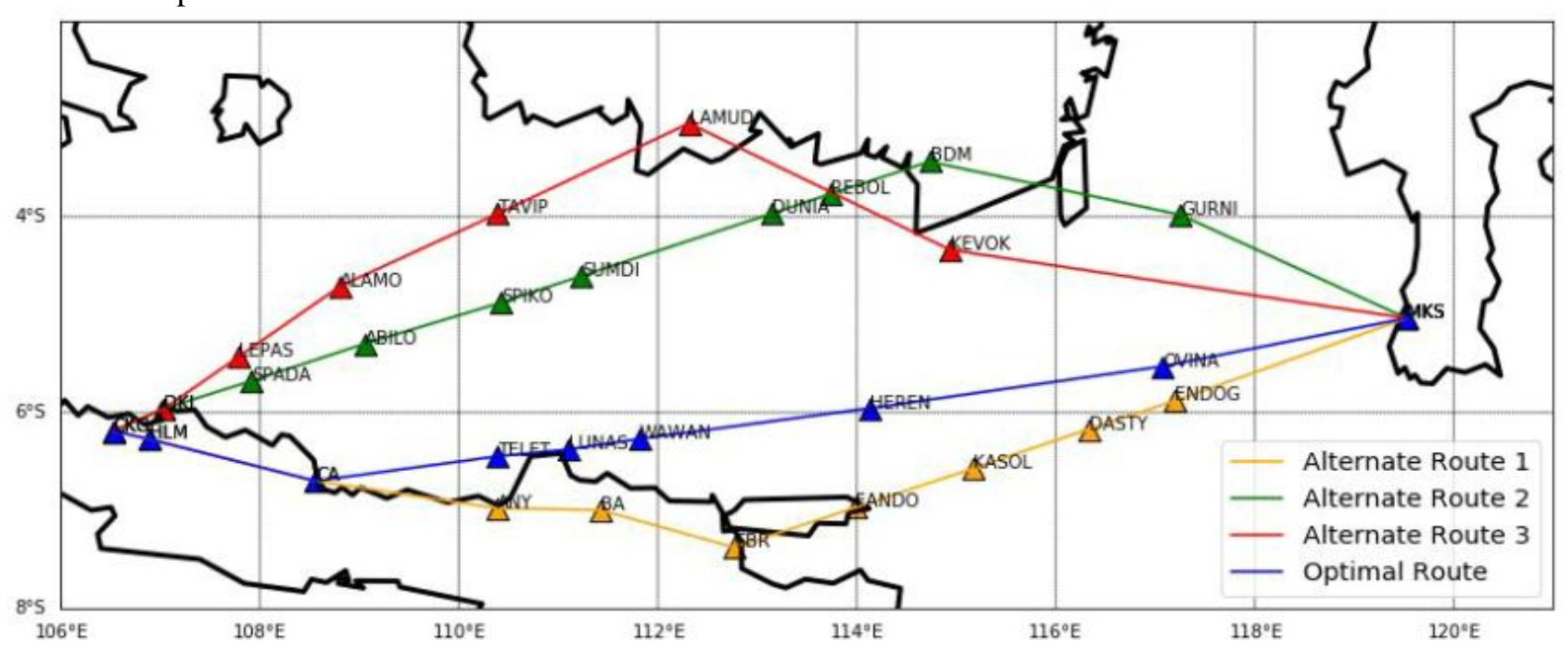

Figure 5. The optimum and alternate routes of Jakarta-Makassar Flight.

Figure 6 shows the correlation between the flight duration of a flight from Jakarta to Makassar using 1 optimum route and 3 alternate routes over the change of ground speed. During normal conditions, the optimal route will require 2 hours, but if there is a tailwind in average of more than $20 \mathrm{kts}$ generated by the 
weather conditions along the waypoints in alternate route 1 and 2 it, it will cause decrease the duration of flight by less than 2 hours and the alternate route will become more profitable to fly than the original route.

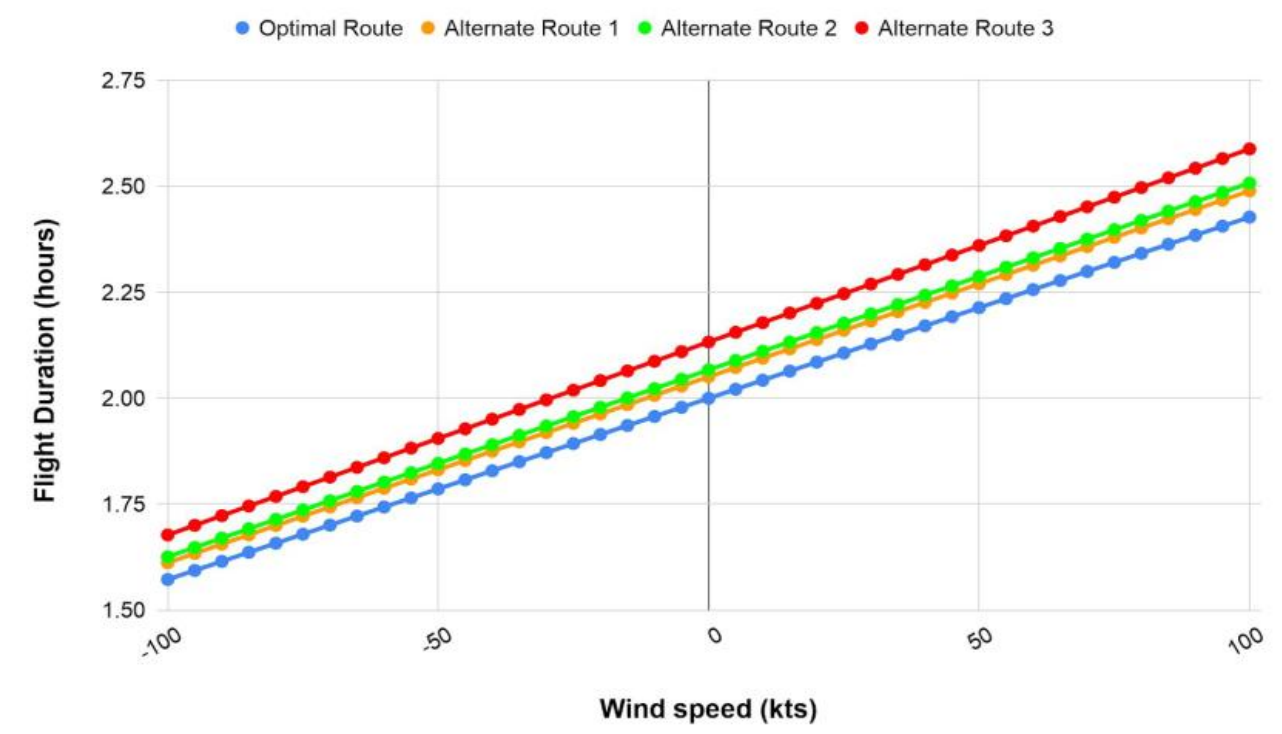

Figure 6. Diagram of Correlation between Wind speed and Flight Duration of route from Jakarta to Makassar.

For the alternate route 3 , the tailwind needs to have an average bigger than 30 kts to achieve 2 hours less flight duration. The navigation log below shows the total flight duration decreased by 15 second, flight duration will continue to decrease if the tailwind becomes stronger.

Using slope rule the gradient of each route can be found, then using line equation to find the intersect. After completing the line equation then it will be able to find when will the alternate route line intersect with the optimum route line.

Table 3. Wind speed needed for alternate route to become optimum route.

\begin{tabular}{|c|c|c|c|c|c|}
\hline & & Optimum Route & Alternate Route 1 & Alternate Route 2 & Alternate Route 3 \\
\hline & $\mathrm{m}$ & 0,004 & 0,004 & 0,004 & 0,005 \\
\hline & $\mathrm{C}$ & 2.00 & 2.05 & 2.07 & 2.13 \\
\hline $\begin{array}{l}\text { If } \\
\text { Yoptimum=Yalternate }\end{array}$ & $\mathrm{X}$ & & -454.5454545 & -500 & -476.3636364 \\
\hline If $\mathbf{Y}=\mathbf{C}$ optimum & $X$ & & -11.5660421 & -15.18987342 & -29.18894831 \\
\hline
\end{tabular}

Note: $\mathrm{m}=$ gradient, $\mathrm{c}=$ intersect, $\mathrm{X}=\mathrm{X}$ value or wind speed at intersection point

From Table 3, at the wind speed of $-454.55 \mathrm{kts}$ or tailwind of $454.55 \mathrm{kts}$, the Optimum route and Alternate route 1 will intersect or mean both routes will have the exact same flight duration. For the optimum route and flight route 2 both routes need to have average speed of $-500 \mathrm{kts}$ or tailwind of $500 \mathrm{kts}$. For alternate route 3 the $x$ intersection point is in $-476.36 \mathrm{kts}$ or tailwind of $476.36 \mathrm{kts}$. With all the windspeed need to be so massive, this condition is most likely impossible to happen as it will be too risky for the flight in to fly in such as massive wind.

From the Table 3 also can be obtained the minimum speed for the alternate route to be more optimal than the optimum route. Thus, for the alternate route 1 it needs at least $-11.57 \mathrm{kts}$ of wind speed or $11.57 \mathrm{kts}$ of tailwind in this route to be present during flight. For alternate route 2 it needs 15.19 kts of tailwind to become more optimum than the optimum route generated by the search engine program. For alternate route 3 it will need at least $-29.19 \mathrm{kts}$ of wind speed present.

\subsection{Discussion}

In our case study, the resulted optimum route is the same route that had been used by many airlines for flight from Jakarta to Makassar. The total flight distance for this flight is 788 Nautical Miles (NM) and with the average flight duration of 2 hours, so the average speed of the aircraft is 394 knots (kts) for the whole flight. The search engine generated a navigation log that also calculated the fuel consumption. For this flight, 
the fuel consumption is 1275 gallons of fuel which will cost around Rp. 37.3 million.

From the restricted airspace example, the search engine calculating the ASHTAM being release and manages to get a redirected route that avoids the volcanic ash but does not have too significant increase in flight distance, the redirected route can be reached in 2 hours 4 minutes time and consume 1317 gallons of fuel that cost Rp. 38.5 million, so the redirect route will increase the operational cost by 1.2 million.

For route optimization analysis, 4 routes had been selected, 1 is the optimum route and 3 alternate routes that have similar distance as the optimum route. The analysis shows how much the flight duration of the routes differ based on the wind speed during the cruising phase of the flight, the wind speed range used in this study is from $-100 \mathrm{kts}$ to $100 \mathrm{kts}$ with $5 \mathrm{kts}$ range per analysis sample.

All the route analysis sample is plotted in the one chart and finding the gradient and the line equation of each route, using the line equation then it will be possible to know when the optimum route line and the alternate route line will intersect to show in which speed of wind will the alternate route become as optimum as the optimum route.

For the alternate route 1 , the speed in both routes need to be at $-454.5 \mathrm{kts}$ or tailwind of $454.5 \mathrm{kts}$, and for alternate route 2 it needs to be $500 \mathrm{kts}$ and $476.3 \mathrm{kts}$ of tailwind for alternate route 3 to have the same flight duration as the optimum route. From the analysis, it can be obtained how many percent the alternate routes will cost based on the optimal route in normal wind condition.

If all the routes are in the zero-wind condition, when a flight takes the alternate routes, the flight duration will be $2.54 \%$ longer, to become more optimum, the alternate route 1 needs to have a tailwind of 11.57 kts. For alternate route 2, in normal condition the flight duration will be $3.35 \%$ longer and it needs to have a tailwind of 15.19 kts to have a shorter flight duration of less than 2 hours, for alternate route 3 , in normal wind condition this route will be $6.65 \%$ longer than the optimum route and need a weather that generate wind that flow into the direction of the flight that is stronger than $29.19 \mathrm{kts}$.

\section{Conclusion and Recommendation}

The research can develop a route search engine program based on the dynamic parameter such us NOTAM and weather data. The optimum route is confirmed with the record from airlines routes for their operation. The search engine is also capable of adding airspace restriction parameters to the calculation. The generated navigation log will avoid the restricted airspace and select the most optimum route that does not cross the restricted airspace to ensure the flight safety and obeying the NOTAM release. The wind parameter in the weather data also affected the resulted flight route by the search engine and the route analysis show the search engine will generate the most optimum route in the given wind parameter.

In case study, during normal conditions the optimum route is $2.54 \%, 3.35 \%, 6.66 \%$ shorter than the alternate route 1,2 and 3 . Alternate route 1 needs a tailwind of $11.57 \mathrm{kts}$, alternate route 2 needs $15.19 \mathrm{kts}$ and alternate route 3 needs 29.19 kts to become more optimum.

From the study, there are few recommendations to further enhance the search engine. First is to add calculation of the vertical flight phase of a flight to have more accurate flight duration. The vertical flight phase will also affect the fuel consumption as take-off and climbing will increase the fuel consumption. Second, the program should equip with Application Programming Interface (API) of actual weather data for each waypoint and airways. With API data the search engine will be able to generate more accurate route results.

\section{Reference}

[1] D. Ferro, V. Roan, P. Haas, and F. Rollet, "Method and device for creating an aircraft flight plan." Google Patents, 2015.

[2] M. J. Gibbs, D. Van Omen, M. B. Adams, K. L. Chase, D. E. Lewis, and D. E. McCrobie, "Method and system for entering data within a flight plan entry field." Google Patents, 2005.

[3] F. Coulmeau, "Method of creating and updating an ATC flight plan in real time to take account of flight directives and implementation device." Google Patents, 2014.

[4] L. Agam and D. Agam, "System for producing a flight plan." Google Patents, 2009.

[5] H. Badli and R. Ghosh, "Method and system for managing flight plan data." Google Patents, 2010.

[6] D. McNally et al., "Dynamic weather routes: two years of operational testing at American Airlines," Air Traffic Control Q., vol. 23, no. 1, pp. 55-81, 2015.

[7] A. Klein, L. Cook, B. Wood, and D. Simenauer, "Airspace capacity estimation using flows and weatherimpacted traffic index," in 2008 Integrated Communications, Navigation and Surveillance Conference, 2008, pp. 1-12.

[8] W. Shijin, C. A. O. Xi, L. I. Haiyun, L. I. Qingyun, H. Xu, and W. Yanjun, "Air route network optimization in fragmented airspace based on cellular automata," Chinese J. Aeronaut., vol. 30, no. 3, pp. 1184-1195, 2017.

[9] L. Wang, W. Wang, F. Wei, and Y. Hu, "Research on the Classification of Air Route Intersections in the Airspace of China," Transp. Res. Rec., vol. 2673, no. 2, pp. 243-251, 2019.

[10] A. Akgunduz, B. Jaumard, and G. Moeini, "Deconflicted air-traffic planning with speed-dependent fuelconsumption formulation," IEEE Trans. Intell. Transp. Syst., vol. 19, no. 6, pp. 1890-1901, 2017. 
[11] A. Bombelli, L. Soler, E. Trumbauer, and K. D. Mease, "Strategic Air Traffic Planning with Fréchet distance aggregation and rerouting," J. Guid. Control. Dyn., vol. 40, no. 5, pp. 1117-1129, 2017.

[12] C. Bongiorno, G. Gurtner, F. Lillo, R. N. Mantegna, and S. Miccichè, "Statistical characterization of deviations from planned flight trajectories in air traffic management,” J. Air Transp. Manag., vol. 58, pp. 152-163, 2017.

[13] M. Y. Pusadan, J. L. Buliali, and R. V. H. Ginardi, "K optima Clustering as Determination of Optimum Flight Route," in 2018 International Conference on Computer Engineering, Network and Intelligent Multimedia (CENIM), 2018, pp. 299-304.

[14] M. Y. Pusadan, J. L. Buliali, and R. V. H. Ginardi, "Optimum partition in flight route anomaly detection," Indones. J. Electr. Eng. Comput. Sci., vol. 14, no. 3, pp. 1315-1329, 2019.

[15] J. Kang, K. Choi, Y. Kim, and H. Yang, "A Method of Integrating Information for SWIM," Proc. - 2017 IEEE 13th Int. Symp. Auton. Decentralized Syst. ISADS 2017, pp. 195-198, 2017, doi: 10.1109/ISADS.2017.30.

[16] S. Ayhan and P. Comitz, "Swim interoperability with flight object mediation service," in 2009 IEEE/AIAA 28th Digital Avionics Systems Conference, 2009, pp. 6--D.

[17] B. Neumayr, E. Gringinger, C. G. Schuetz, M. Schrefl, S. Wilson, and A. Vennesland, "Semantic data containers for realizing the full potential of system wide information management," AIAA/IEEE Digit. Avion. Syst. Conf. Proc., vol. 2017-Septe, 2017, doi: 10.1109/DASC.2017.8102002.

[18] X. Lu and T. Koga, "SWIM concept-oriented information integration for air traffic surviellance," in 2017 IEEE 6th Global Conference on Consumer Electronics (GCCE), 2017, pp. 1-2.

[19] J. C. H. Cheung, "Flight planning: node-based trajectory prediction and turbulence avoidance," Meteorol. Appl., vol. 25, no. 1, pp. 78-85, 2018.

[20] ““"Wayback

Machine." https://web.archive.org/web/20140725005129/http://www.boeing.com/assets/pdf/commercial/startup/pdf/737ng _perf.pdf (accessed Aug. 13, 2020).

[21] "Pertamina Aviation." https://www.pertamina.com/aviation/News.aspx?p=price (accessed Aug. 14, 2020).

[22] Flightradar24, "Live Flight Tracker - Real-Time Flight Tracker Map." https://www.flightradar24.com/data/flights/ga616 (accessed Aug. 14, 2020). 